\title{
Risk factors for relapse and recurrence of ulcerative colitis and Crohn's disease
}

\author{
PAUL RUTGEERTS, MD, PHD
}

PRUTGEERTS. Risk factors for relapse and recurrence of ulcerative colitis and Crohn's disease. Can J Gastroenterol 1993;7(2):215-218. The course of Crohn's disease and ulcerative colitis is characterized by periods of active disease, alternating with periods of quiescence. Risk factors for relapse of inflammatory bowel disease have not yet clearly been defined, but for Crohn's disease as well as for ulcerative colitis the pattern of the disease seems the most important factor. Other factors such as intake of nonsteroidal anti-inflammatory drugs, respiratory infection and psychological stress seem to be less important relapse provoking factors. In Crohn's disease the location and spread of the disease seem important. Total colectomy cures ulcerative colitis while Crohn's disease usually recurs following surgical resection of the lesions. After curative ileal resection, new Crohn's lesions' recur in the neoterminal ileum within weeks to months. The severity of early recurrence will determine the subsequent clinical evolution. Recurrence is fecal stream dependent as lesions recur only if there is passage of fecal stream through the neoterminal ileum and the ileocolonic anastomosis.

Key Words: Crohn's disease, Endoscopy, Recurrence, Relapse, Ulcerative colitis

\section{Facteurs de risque à l'égard de la rechute et de la récurrence de} la colite ulcéreuse et de la maladie de Crohn

RÉSUMÉ: L'évolution de la maladie de Crohn et de la colite ulcéreuse est caractérisée par des périodes d'exacerbations et d'accalmies successives. Les facteurs de risque à l'égard de la rechute de la maladie intestinale inflammatoire n'ont pas encore été clairement définis, mais pour la maladie de Crohn et pour la colite ulcéreuse, le modèle lui-même de la maladie semble le facteur le plus important. D'autres facteurs, comme la prise de médicaments anti-inflammatoires non stéroïdiens, l'infection respiratoire et le stress psychologique, semblent moins importants comme facteurs inducteurs de la rechute. Dans la maladie de Crohn, le siège et l'étendue de la maladie semblent importants. Le colectomie totale guérit la colite ulcéreuse alors que la maladie de Crohn récidive généralement suite à une résection chirurgicale des lésions. Après une résection iléale curative, de nouvelles lésions de Crohn apparaissent au niveau de l'iléon néoterminal dans les semaines et les mois qui suivent. La gravité des récurrences précoces déterminera l'évolution clinique subséquente. La récurrence dépend de l'écoulement fécal puisque les lésions ne reviennent que s'il y a passage de selles par l'iléon néoterminal et l'anastomose iléocolique.

Department of Medicine, Division of Gastroenterology, University Hospital Gasthuisherg, University of Leuven, Leuven, Belgium

Correspondence and reprints: Dr P Rutgeerts, Professor of Medicine, Department of Gastroenterology, University Hospital Gasthuisberg, Herestraat 49, 3000 Leuven, Belgium. Telephone 32-16-214225, Fax 32-16-214799
ROHN'S DISEASE AND ULCERA-
tive colitis are two chronic idiopathic inflammatory bowel diseases (IBD) characterized by frequent relapses of disease activity and periods of remission. Crohn's disease recurs almost always after ileal resection and partial colectomy and ileocolonic anastomosis for complicated Crohn's ileitis. Ulcerative colitis can be cured by total proctocolectomy with ileostomy or colectomy with ileoanal pouch anastomosis. Before defining risk factors for relapse and recurrence of IBD, clear definitions must be provided. The definitions proposed by Lee (1) in his review paper are used here.

Crohn's recurrence: The appearance of objective signs - defined radiologically, endoscopically or pathologically - of Crohn's disease in the bowel of a patient who has previously had a resection of all macroscopically diseased tissue.

Crohn's relapse: The appearance of the clinical features of Crohn's disease after a symptom-free interval in patients with known disease, provided that other unrelated causes of these symptoms have been excluded.

The term 'recurrence' can only be used for Crohn's disease as surgery for ulcerative colitis always involves removal of the entire colon, which means definitive cure for the patient. Other procedures like ileorectal anastomosis after partial colectomy leave inflamed mucosa behind and a flare in the rectum should be considered relapse. The term recurrence can also 
be used only after radical or curative resection. A radical resection involves the excision of a sufficient length of normal bowel from either side of the diseased gut, together with the lymph nodes draining the region, to remove all the disease. Nowadays the segment of normal bowel removed is rather limited $(5$ to $15 \mathrm{~cm}$ ) in order to avoid short bowel syndrome upon repeated surgery. This type of resection can still be called 'curative resection'. Local or segmental resections are designed to remove segments of Crohn's disease which are causing the symptoms such as fistulae and obstructions. No attempt is made to carry out a curative resection and areas of inflammation may be left behind. Bypass operations divert the fecal stream from the diseased segment to ameliorate the inflammation in the dysfunctioning gut.

Risk factors for relapse of ulcerative colitis have not been defined accurately. The main factor determining outcome in patients with ulcerative colitis is the individual disease pattern (2). Besides disease pattern other factors thought to be responsible for relapses of ulcerative colitis are intake of nonsteroidal anti-inflammatory drugs (NSAIDs) (3) and upper respiratory tract infections (4). Psychological stress may be a relapse provoking feature although statistically significant data have not been gathered. An important factor also seems to be the quality of remission of ulcerative colitis. If clinical activity of the disease is accompanied by endoscopic and histologic remission there is less chance for relapse than with incomplete healing.

Relapse provoking factors in Crohn's disease are also incompletely understood. Not only does disease pattern play an important role but the location of the disease is also important (5). Colonic disease relapses more often than ileal disease, whereas diffuse Crohn's disease is more aggressive than segmental disease. Persistent abnormality of biological activity parameters is also predictive of early relapse (6), whereas the influence of NSAIDs intake on relapse is not as well documented as in ulcerative colitis (although NSAIDs by themselves may cause lesions closely mimicking Crohn's disease of the small bowel).

Clinical factors predictive of recurrence of Crohn's disease after surgery have been thoroughly investigated (7) but they have not been identified with certainty. Factors thought to be associated with recurrence are age at onset of the disease, duration of Crohn's disease before resection, previous bowel resections, indication for surgery, extent of resection performed, location of the disease, involvement of the disease at the resection margins, the presence of granulomas and perioperative blood transfusions.

The location of disease is important. The recurrence rate of Crohn's disease is much lower after resection with ileostomy than after resection with ileocolonic anastomosis. In patients without ileostomy, recurrence rates are lowest with the longest preoperative disease duration. An attractive concept is also the different recurrence behaviour between patients with fibrostenotic disease and patients with perforating (abscess, fistula) disease as reported by Greenstein et al (8). As recurrent disease tends to be located in the region of the ileocolonic anastomosis, which can easily be reached by colonoscopy, endoscopic and histopathological studies seemed to be the best approach to study the natural history of Crohn's disease after surgery. The first step in the investigation was a systematic endoscopic 'cross section' study of a large group of patients that had been treated by surgery for Crohn's disease of the distal ileum and partial colectomy with ileocolonic anastomosis over a 10 year period (9). One hundred and fourteen patients were studied. They all had been treated by partial ileal resection, partial colectomy and ileocolonic anastomosis for Crohn's disease.

The incidence of recurrent Crohn's lesions in this group amounted to $72 \%$ of the patients examined within one year of the curative resection, $79 \%$ of the patients examined one to three years after surgery and $77 \%$ of the patients examined more than three years after surgery. Recurrent lesions were confined to the neoterminal ileum and the anastomosis in $88 \%$ of the patients. This means that lesions were found as frequently within the first year after surgery as in subsequent years. The nature, however, of the lesions differed greatly.

Small aphthous ulcers were the first macroscopically objective signs of recurrent disease occurring in $77 \%$ of 21 patients with recurrent disease in the first year after the operation. More severe lesions were seldom found during this period ( $23 \%$ of patients). These early aphthous ulcers were often located at the crest of thickened folds occurring in clusters or in linear arrays in some patients.

Early histological changes include blunting of the villi and a patchy or focal inflammatory infiltrate. In $25 \%$ of the specimens obtained in early lesions the inflammatory infiltrate was mainly composed of eosinophils.

In more than half of the patients examined one to three years after surgery, lesions were more severe and consisted of nodules, large longitudinal, serpiginous and oval ulcers and in one third the neoterminal ileum showed some degree of narrowing. In $43 \%$ of patients endoscoped three to 10 years after surgery, an ulcerated stenosis had already developed. Frequently ulcers radiating from the stricture into the colonic segment were observed.

These studies showed that Crohn's disease lesions recur in the neoterminal ileum very early after surgery and sug. gest that mild early lesions evolve to severe lesions in the ensuing years. A logical step in the studies, therefore, was the follow-up of early lesions. A prospective endoscopic and histological follow-up study was, therefore, carried out in 89 Crohn's patients sub. jected to curative ileal resection (10). The study attempted to determine when patients with asymptomatic endoscopic recurrence develop symptoms and complications, whether and when patients without early endoscopic recurrence develop recurrence, and whether endoscopic lesions disappear.

The follow-up protocol included an ileocolonoscopy within the first year of resection and a six-monthly clinical and laboratory follow-up. In all patients 
a follow-up ileocolonoscopy was carried out at three and six years after surgery.

The following ileal score system was used to evaluate the neoterminal ileum at endoscopy: iO - no lesions; il - fewer than five aphthous lesions; i2 - more aphthous lesions but normal mucosa between the lesions or a few skip areas of larger lesions or lesions confined to the ileocolonic anastomosis (ie, less than $1 \mathrm{~cm}$ ); $\mathrm{i} 3$-diffuse aphthous ileitis with diffusely inflamed mucosa; i4 diffuse inflammation with already larger ulcers, nodules and/or narrowing.

The recurrence rates were analyzed using actuarial techniques. The years after treatment were set out with the number of patients free from endoscopic, symptomatic, biological and surgical recurrence at the beginning of each follow-up year. All patients completed at least the three year follow-up period. From the fourth year on, proportional recurrence was calculated in the patients followed-up during that year. Only 24 (27\%) had no recurrence at one year, ie, $73 \%$ presented with unequivocal recurrent lesions, usually aphthous ulcers. Symptoms recurred in $20 \%$ within one year, biological signs of inflammation in $28 \%$ and reoperation in 3\%. The life-table analysis shows a biphasic curve for symptomatic recurrence. At three years the endoscopic recurrence rate was $85 \%$ and the clinical recurrence rate was $34 \%$. In this cohort of patients the endoscopic score of the neoterminal ileum at endoscopy within one year after surgery was the most powerful risk factor to predict symptomatic recurrence and complications. Other significant risk factors were preoperative disease activity, the indication for surgery and the number of resections.

When the data are stratified for preoperative disease activity - the most powerful clinical risk factor - only the endoscopic score kept its predictive value.

Outcome was then analyzed separately for the groups with different endoscopy scores. The evolution was not different for scores i0 and il, but between these groups and other groups there was a statistically different evolu- tion. Patients with no or very mild lesions (iO and il) at endoscopy one year after surgery did very well and remained symptom free. Patients with clearly progressive (i3 and i4) Crohn's disease recurrence at endoscopy had a poor prognosis. They developed early symptoms and were prone to complications of the disease in subsequent years. The disease in patients with score i2 evolved in some towards symptomatic recurrence, while in others it remained indolent.

The next issue to address was whether aphthous ulcers recurring after surgery originate from inflammation left behind at surgery or whether these are truly 'new lesions'. To investigate this the neoterminal ileum was studied both intraoperatively and postoperatively in 22 patients (9). The patients were treated by 'curative' terminal ileal resection and right hemicolectomy with ileocolonic anastomosis. At surgery the ileal segment to be used as neoterminal ileum was turned inside out, the mucosa was carefully examined in order not to leave macroscopic disease behind, and two large mucosal biopsies were taken proximally to the anastomotic line, one at the mesenteric and another at the antimesenteric border. Ten cancer patients were studied as controls.

Each of the three following histological abnormalities had to be present in order to make a diagnosis of unequivocal ileal inflammation: a disturbed villus architecture; epithelial cell alterations at the lateral side of the villi; presence of an inflammatory cell infiltrate, including neutrophilic and eosinophilic polymorphs as well as mononuclear cells. More severe lesions were extensive inflammation, ulcerations and granulomas.

On peroperative inspection all 22 patients had normal mucosa in the ileal segment used as neoterminal ileum. Nineteen of the patients had perfectly normal histology on examination of the intraoperative biopsies and in 16 the cut margins were free from disease. At ileocolonoscopy six months after resection all but one of the patients had clear-cut macroscopic inflammation in the neoterminal ileum extending over
$15 \mathrm{~cm}$ (range 4 to $30 \mathrm{~cm}$ ) of the neoterminal ileum. Twenty patients had unequivocal microscopic inflammation in the same area and three patients had granulomas in their biopsies.

It may be concluded that the presence or absence of microscopic inflammation in the neoterminal ileum at surgery has no predictive value for recurrence and the lesions are indeed 'new'. These findings were confirmed recently by two peroperative endoscopy studies $(12,13)$.

An important question is which factors are responsible for recurrence of early lesions in the neoterminal ileum. One factor studied is the fecal stream (11). This study was carried out in six Crohn's patients undergoing ileal resection and in whom a two-step procedure was necessary. One patient dropped out from the study because in the resection specimen an adenocarcinoma was detected.

Because of extensive fistulation to the rectum a temporary diverting stoma was planned. After 'curative' resection and ileocolonic anastomosis, a terminal ileostomy was constructed 25 to $35 \mathrm{~cm}$ proximally to the anastomosis, excluding the neoterminal ileum, anastomosis and colon from the intestinal transit. The segment used as neoterminal ileum was examined macroscopically, and biopsies and cut margins were also studied. After six months of exclusion the neoterminal ileum and colon were examined by ileocolonoscopy and biopsies. At this time, the normal transit was restored and six months after reanastomosis the patients underwent a control endoscopy with another set of biopsies.

The control group comprised 75 patients who underwent a one-step procedure during the same period and consented to a follow-up colonoscopy within six months after resection. All five patients had severe ileorectal fistulas, the extent of resection ranged from 15 to $40 \mathrm{~cm}$ and the cut margins were negative.

In these five patients the neoterminal ileum was completely normal during exclusion of the fecal stream and histology did not show Crohn's inflammation. Within six months after 
reanastomosis all five patients had clear cut endoscopic recurrence and severe microscopic disease. In the case control group 53 of 75 patients ( $71 \%$ ) had endoscopic lesions within six months. The differences were highly significant.

\section{CONCLUSIONS}

- Endoscopic lesions recur in the neoterminal ileum within months after curative ileal resection for Crohn's ileitis

ACKNOWLEDGEMENTS: The present studies were made possible by a grant of the FGWO: 3.0061.92.

\section{REFERENCES}

1. Lee ECG, Papaioannou N. Recurrences following surgery for Crohn's disease. Clin Gastroenterol 1980;9:419-38.

2. Edwards FC, Truelove SC. The course and prognosis of ulcerative colitis. Gut 1963:4:299-315.

3. Rampton OS, McNeil NI, Sarner M. Analgesic ingestion and other factors proceding relapse in ulcerative colitis. Gut 1983;24:187-9.

4. Mee AS, Jewell DP. Factors inducing relapse in inflammatory bowel disease. Br Med J 1978;ii:801-2.

5. Farmer RG, Whelan G, Fazio VW. Long-term follow-up of patients with
- Aphthous ulcers are the earliest macroscopically identifiable lesions

- The severity and extent of these early lesions predict the subsequent clinical evolution of the disease

- These early lesions do not originate from inflammation left behind at surgery but are 'new lesions'

- Disease recurs only if the fecal stream passes through the neoterminal ileum and the ileocolonic anastomosis.

Early recurrent Crohn's disease is

Crohn's disease. Relationship between the clinical pattern and prognosis. Gastroenterology 1985;88:1818-25.

6. Brignola C, Campieri M. Bazzocchi G, Farrugia P, Tragnone A, Lanfranchi GA. A laboratory index for predicting relapse in asymptomatic patients with Crohn's disease. Gastroenterology 1986;91:1490-4

7. Williams JG, Wong WD, Rothenberger DA, Goldberg SM. Recurrence of Crohn's disease after resection. Br J Surg 1991;78:10-9.

8. Greenstein AJ, Lachman P, Sachar $\mathrm{DB}$, et al. Perforating and non-perforating indications for repeated resections in Crohn's disease: Evidence for two clinical forms. Gut 1988;29:588-92.

9. Rutgeerts P, Geboes K, Vantrappen G, Kerremans R, Coenegrachts JL, Coremans G. Natural history of recurrent Crohn's disease at the the best model available to study the pathogenesis of Crohn's disease and to assess the value of therapeutic modalities for recurrence prevention. Recurrence prevention could be the prevention of recurrence of early new lesions, prevention of evolution of early lesions to symptomatic recurrence, prevention of complications and prevention of repeated surgery. It is clear that every effort should be made to prevent the development of early lesions.

ileocolonic anastomosis after curative surgery. Gut 1984;25:665-72.

10 Rutgeerts P, Geboes K, Vantrappen G, Beyls J, Kerremans R, Hiele M. Predictability of the postoperative course of Crohn's disease. Gastroenterology 1990;99:950-63.

11. Rutgeerts P, Geboes K, Peeters M, et al. Effect of faecal stream diversion on recurrence of Crohn's disease in the neoterminal ileum. Lancet 1991;338:771-4

12. Lescut D, Vanco D, Colombel JF. Influence des lesions endoscopiques sur les recidives endoscopiques anastomotiques au cours de la maladie de Crohn. Gastroenterol Clin Biol 1990;14:A20.

13. Olaison G, Smedh K, Sjödahl R. Natural course of Crohn's disease after ileocolonic resection in endoscopically visualized ileal ulcers preceeding symptoms. Gut 1992;33:331-5. 


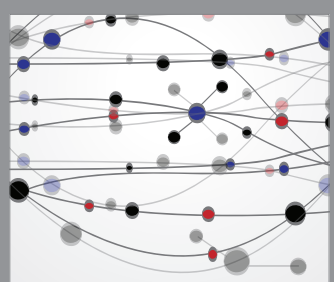

The Scientific World Journal
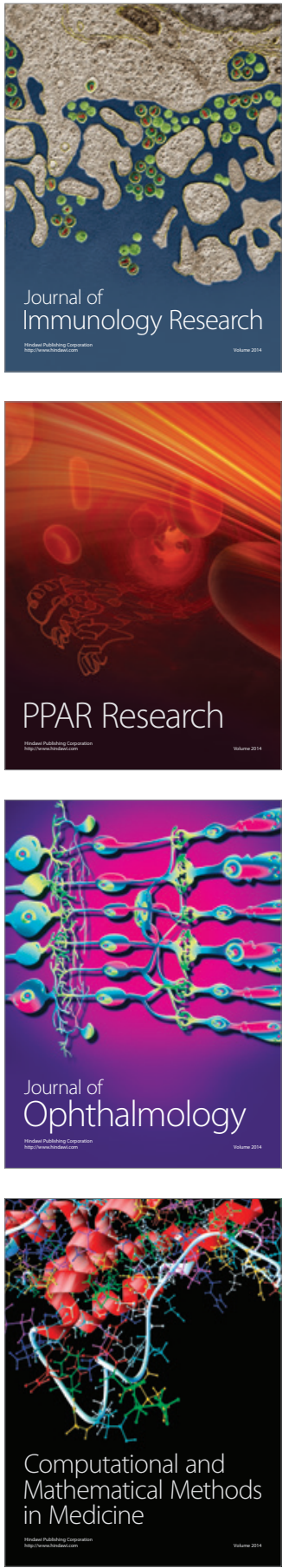

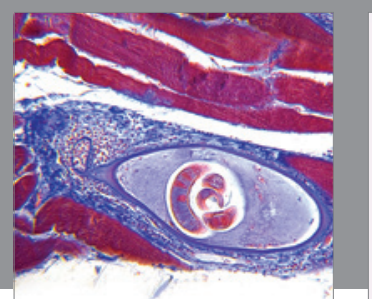

Gastroenterology Research and Practice

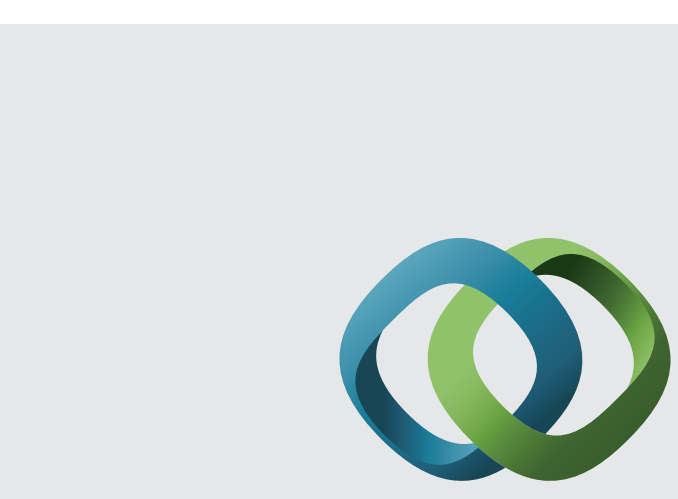

\section{Hindawi}

Submit your manuscripts at

http://www.hindawi.com
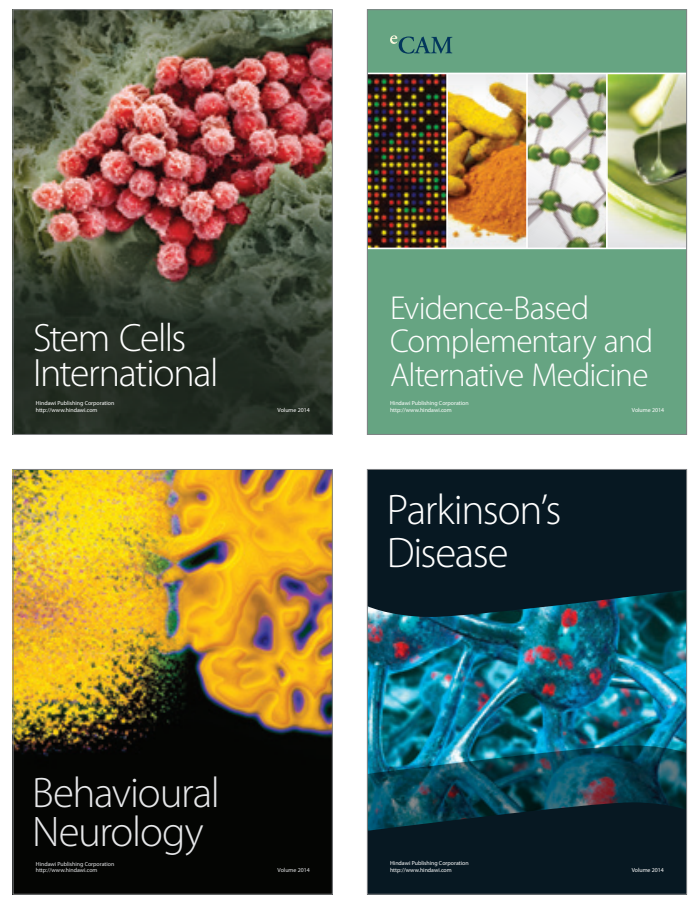
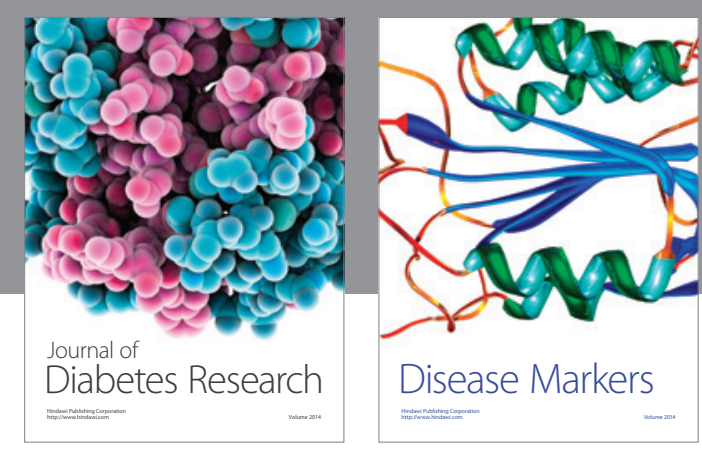

Disease Markers
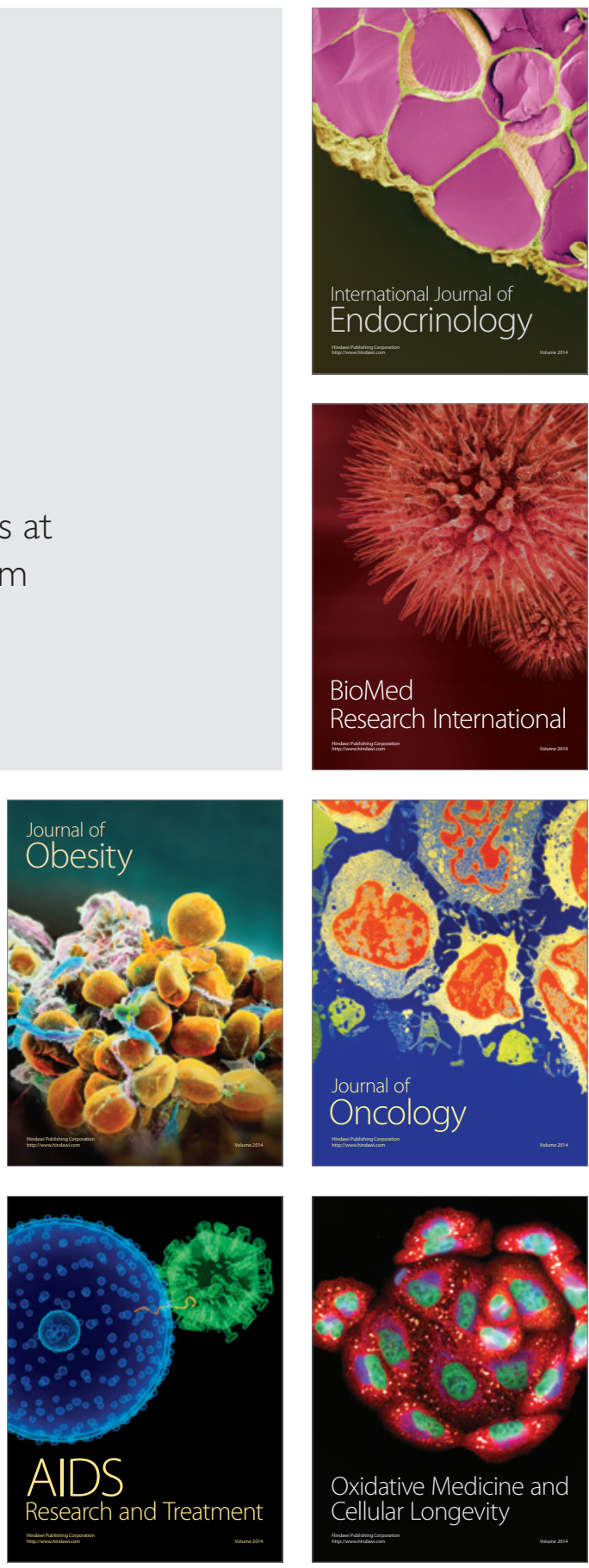